\title{
PAPERS
}

\section{Oesophagitis is as important as oesophageal stricture diameter in determining dysphagia}

\author{
M Dakkak, R C Hoare, S C Maslin, J R Bennett
}

\section{Abstract}

It is a common observation that stricture patients with severe dysphagia may have a wide lumen, while others with a narrow stricture have few swallowing complaints. In 64 patients with benign oesophageal stricture the dysphagia score (determined by questionnaire and by a test meal both based on nine different items of food scored according to their solidity) was compared with the diameter of the stricture measured radiologically by premeasured barium spheres. There was evidence of an association, but the correlation coefficient ( $r$ ) was $0.544(p=0.0001)$, suggesting that the diameter of the stricture is an important, although not the sole, determinant of dysphagia. Stricture diameter explains $29.6 \%\left(r^{2}\right)$ of variation in dysphagia score. The patients (mean dysphagia score 71 of a maximum possible 90 ) were divided into three groups according to the severity of oesophagitis (19 patients had minimal, 22 moderate and 23 severe oesophagitis). Analysis revealed the mean dysphagia score to be $83,73,59$ in each group respectively. Dysphagia score of each group was significantly different from the others (Kruskal-Wallis test). Relating the dysphagia score to stricture diameter for each group gives correlation coefficient $r=0.379$ $(p=0.110)$ in the minimal oesophagitis group, $r=0.651(p=0.001)$ in the moderate group, $r=0.583(p=0.004)$ in the severe group. If both diameter and severity of oesophagitis are included then $66.0 \%$ of the variation can be explained. It is concluded that the degree of oesophagitis is as important as luminal diameter in determining swallowing ability.

(Gut 1993; 34: 152-155)

Dysphagia, which is the cardinal symptom of patients with oesophageal stenosis, is generally perceived to be a manifestation of obstruction by luminal narrowing. This view has occasionally been questioned in certain individual patients with severe dysphagia but a wide lumen, or in those who had a narrow stricture but few swallowing complaints. It is recognised that reflux oesophagitis in the absence of stricture may cause dysphagia, but this has not been widely documented until recently.' We set out to determine the influence of both luminal diameter of the stricture and of oesophagitis on the perception of dysphagia in patients with an oesophageal peptic stricture.
TABLE I Dysphagia score

\begin{tabular}{lcc}
\hline Food & $\begin{array}{l}\text { Meal } \\
\text { score }\end{array}$ & $\begin{array}{l}\text { Questionnaire } \\
\text { score }\end{array}$ \\
\hline Water, $200 \mathrm{ml}$ & 1 & 1 \\
Milk, $100 \mathrm{ml}$ & 2 & 2 \\
Custard, $40 \mathrm{~g}(11 / 2 \mathrm{oz})$ & 3 & 3 \\
Jelly, $70 \mathrm{~g}\left(2^{1 / 2} \mathrm{oz}\right)$ & 4 & 4 \\
Scrambled egg, one & 5 & 5 \\
Baked fish, $40 \mathrm{~g}(11 \mathrm{1} / \mathrm{oz})$ & 6 & 6 \\
White bread, one slice & 7 & 7 \\
Apple, one & 8 & 8 \\
Steak, $40 \mathrm{~g}(11 / 2 \mathrm{oz})$ & 9 & 9 \\
Total & 45 & 45 \\
\hline
\end{tabular}

Dysphagia score $=$ meal score + questionnaire score $=$ maximum 90 points.

To be able accurately to study the influence of different factors on dysphagia we devised a detailed numerical scoring system for dysphagia. $^{2}$

\section{Methods}

PATIENTS

We studied 64 patients (mean age 67 years; range 37-84) with benign peptic oesophageal strictures. Their dysphagia was assessed by a dysphagia score based on nine different items of food scored according to their solidity. ${ }^{2}$ Half of the score was obtained from questioning patients regarding the items of food which cause dysphagia; the other half of the score was based on the consumption of a standard test meal (the maximum combined score indicating perfect swallowing is 90) (Table I). All patients had their stricture diameter measured by swallowing graded barium wax spheres of increasing size during radiological monitoring. The largest sphere to pass through the stricture was taken to indicate the stricture's diameter. ${ }^{3}$ Endoscopy was performed by a single investigator who recorded the severity of oesophagitis above the stricture using a modified Savary-Miller classification (Table II). Each patient had all the tests performed within a period of 10 days.

TABLE II Modified Savary-Miller classification for oesophagitis above benign strictures

$\begin{array}{ll}\text { Minimal oesophagitis: } & \begin{array}{c}\text { no inflammation or up to two non- } \\ \text { confluent superficial mucosal lesions. } \\ \text { more than two non-confluent lesions up } \\ \text { to confluent lesions affecting less than } \\ 50 \% \text { of circumference of the lumen. }\end{array} \\ \text { Moderate oesophagitis } \\ \text { confluent or ulcerative lesions affecting } \\ \text { more than } 50 \% \text { of circumference. }\end{array}$




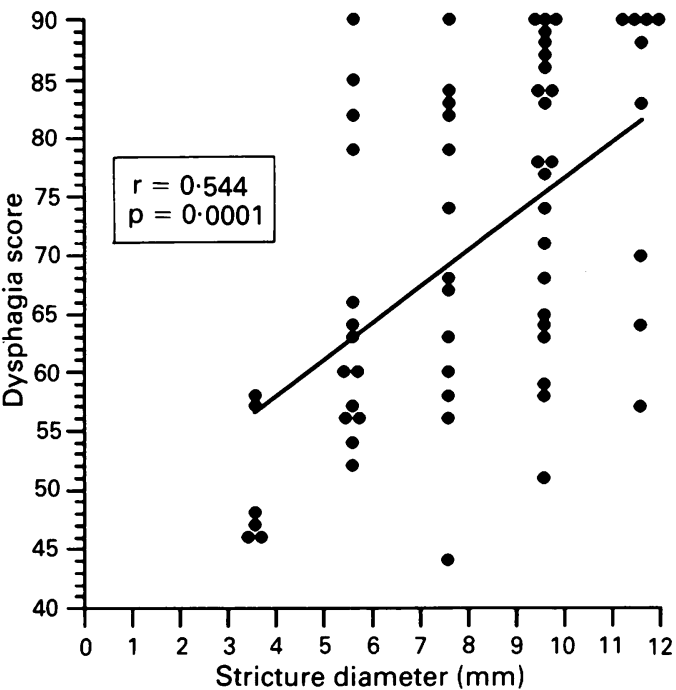

Figure 1: Relationship between the dysphagia score and the diameter of the stricture in all patients.

\section{STATISTICAL METHODS}

The relation between dysphagia score and stricture diameter was investigated using correlation and regression methods for all patients.

This was also done for each category of oesophagitis separately. A regression line can be drawn to represent the relationship between individual patient's dysphagia score and the diameter of their stricture as measured. Such regression lines were calculated and constructed for patients divided up into the degree of oesophagitis visible endoscopically at the time of dilatation.

Comparisons of dysphagia score and stricture diameter between the groups were made using a Kruskal-Wallis test, followed by Wilcoxon's rank-sum tests where overall differences were statistically significant. Coefficients of determination $\left(r^{2}\right)$ were used to measure the proportion of the variation in dysphagia score explained by stricture diameter and severity of oesophagitis at each stage. A generalised linear model, with two

Patients with severe oesophagitis and stricture

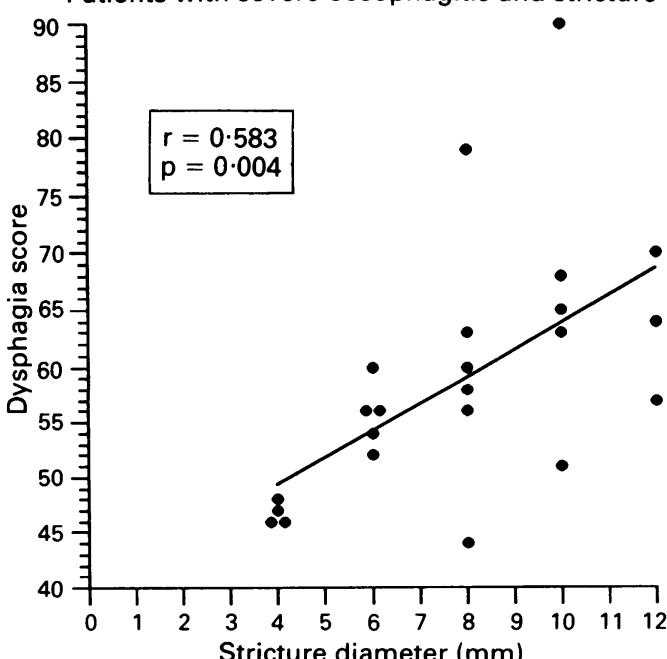

Figure 2: Relationship between the dysphagia score and the diameter of the stricture in patients with benign oesophageal stricture associated with severe oesophagitis.
TABLE III Dysphagia score and oesophagitis

\begin{tabular}{llll}
\hline Oesophagitis & Patients $(n)$ & $\begin{array}{l}\text { Dysphagia } \\
\text { score }\end{array}$ & $\begin{array}{l}95 \% \text { confidence } \\
\text { interval }\end{array}$ \\
\hline Severe & 23 & $58 \cdot 8^{\star} \ddagger$ & $54 \cdot 1$ to $63 \cdot 6$ \\
Moderate & 22 & $72 \cdot 8^{\star} \ddagger$ & $67 \cdot 2$ to $78 \cdot 5$ \\
Minimal & 19 & $82 \cdot 9+\ddagger$ & $79 \cdot 6$ to $86 \cdot 3$ \\
Total & 64 & $70 \cdot 8$ & $67 \cdot 2$ to $74 \cdot 4$ \\
\hline
\end{tabular}

Kruskal-Wallis test

\begin{tabular}{llrl} 
Groups & $\begin{array}{l}\text { Mean } \\
\text { difference }\end{array}$ & $\begin{array}{l}95 \% \text { confidence } \\
\text { interval }\end{array}$ & p value \\
\hline ^Severe and moderate & $14 \cdot 1$ & $7 \cdot 0$ to $21 \cdot 2$ & $0 \cdot 0005$ \\
† Moderate and minimal & $10 \cdot 1$ & $3 \cdot 5$ to $16 \cdot 7$ & $0 \cdot 02$ \\
†Severe and minimal & $24 \cdot 1$ & $18 \cdot 2$ to $30 \cdot 0$ & $0 \cdot 0001$ \\
\hline
\end{tabular}

dummy variables to represent the three severity groups, was used to compare the regression lines in terms of slope and location. ${ }^{+}$

\section{Results}

The mean dysphagia score for all patients was $70 \cdot 8(95 \%$ confidence interval $67 \cdot 2$ to $74 \cdot 4)$. The mean stricture diameter was $8.6 \mathrm{~mm}(95 \%$ confidence interval $\mathbf{7 \cdot 8}-\mathbf{9} \cdot 0 \mathrm{~mm}$ ). A significant linear association was detected between the dysphagia score and the diameter of the stricture $(\mathrm{r}=0.554 ; \mathrm{p}=0.0001)$ (Fig 1$)$

If a correlation is detected between two variables, the square of the correlation coefficient indicates the percentage of the variation in one factor that can be attributed to the other. ${ }^{4}$ In this case $r=0.544, r^{2}=0.296$, indicating that the luminal diameter of the stricture accounts for $29 \cdot 6 \%$ of the variation in the dysphagia score.

Endoscopy classified the patients into three groups: 23 patients had severe oesophagitis, 22 had moderate oesophagitis and 19 had minimal oesophagitis. The dysphagia score for each category of oesophagitis (Table III) was significantly different to that in the other two groups (Kruskal-Wallis test). On the other hand there was no significant difference in stricture diameter between the oesophagitis-severity groups (Kruskal-Wallis test) (Table IV).

When each category of oesophagitis was analysed separately, a linear association was found between the dysphagia score and the diameter of the stricutre: $r=0.583 ; p=0.004$ in the group with severe oesophagitis (Fig 2); $\mathrm{r}=0.657 ; \mathrm{p}=0.001$ in the group with moderate oesophagitis (Fig 3); and $r=0.379 ; p=0.11$ in the minimal group (Fig 4). Data for the three regression lines representing the categories of oesophagitis were analysed together and were shown to be separate from each other in terms of slope and intercept (Fig 5). Thus, as an example a stricture of $8 \mathrm{~mm}$ would give a predicted dysphagia score of 82 if oesophagitis was

TABLE IV Oesophagitis and stricture diameter

\begin{tabular}{|c|c|c|c|}
\hline Oesophagitis & Patients ( $n$ ) & $\begin{array}{l}\text { Stricture } \\
\text { diameter } \mathrm{mm}\end{array}$ & $\begin{array}{l}\text { Confidence } \\
\text { interval } 95 \%\end{array}$ \\
\hline Severe & 23 & $7 \cdot 8$ & 6.7 to $9 \cdot 0$ \\
\hline Moderate & 22 & $8 \cdot 5$ & $7 \cdot 5$ to $9 \cdot 4$ \\
\hline Minimal & 19 & $9 \cdot 2$ & $8 \cdot 0$ to $10 \cdot 3$ \\
\hline Total & 64 & $8 \cdot 4$ & $7 \cdot 8$ to $9 \cdot 0$ \\
\hline
\end{tabular}

Kruskal Wallis test. $\mathrm{p}=0.23$ not significant. 


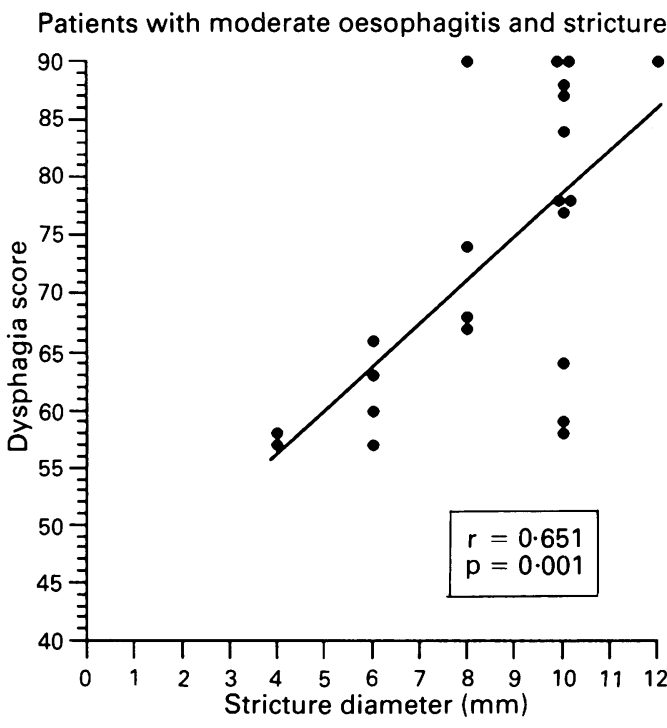

Figure 3: Relationship between the dysphagia score and the diameter of the stricture in patients with benign oesophageal stricture associated with moderate oesophagitis.

minimal, 71 if moderate, but 59 if oesophagitis was severe (Fig 5).

\section{Discussion}

We have used careful, objective measurement of stricture diameter and a detailed numerical score for dysphagia to determine the relationship between these variables. Statistical evaluation indicates that the diameter of the stricture accounts for only $30 \%$ of the variation in dysphagia score, with $70 \%$ unaccounted for. Other investigators found also that linear correlation between dysphagia and stricture diameter was only moderately strong. ${ }^{5}$ It is likely that additional contributory factors will account for at least part of the remaining unexplained variation.

Dysphagia was clearly worse with increasing severity of oesophagitis (Table III). Oesophagitis alone has been demonstrated to be the cause of dysphagia in the absence of stricture. ${ }^{16}$ The mechanism of oesophagitis associated dysphagia remains speculative, but changes in peristaltic

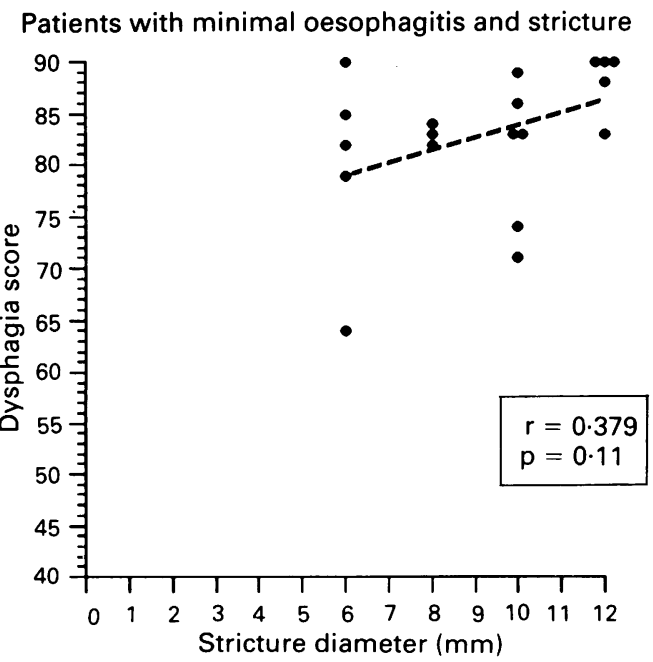

Figure 4: Relationship between the dysphagia score and the diameter of the stricture in patients with benign oesophageal stricture associated with minimal oesophagitis.

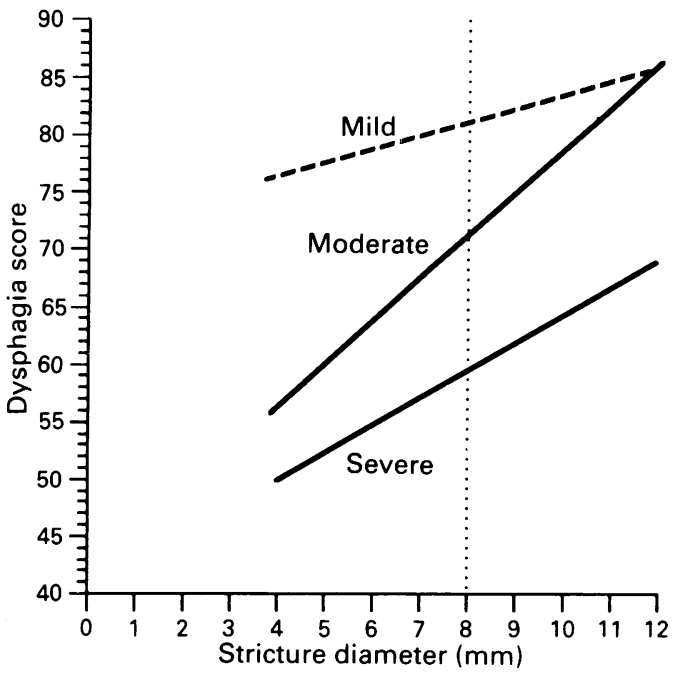

Figure 5: Three regression lines representing the three categories of oesophagitis. The dotted line indicates how the severity of oesophagitis would affect dysphagia in a patient whose stricture diameter measured $8 \mathrm{~mm}$. If his oesophagitis was only minimal his dysphagia score would be 82 , if moderate 71 , but if he had severe oesophagitis it would be only 59.

amplitude, nonpropagated peristalsis or raised oesophageal intraluminal pressure have been suggested. Although peristaltic abnormalities have been postulated to be responsible for dysphagia in patients with oesophagitis, inflammation alone is also a possible explanation.' Whether oesophagitis is the cause or the result of oesophageal peristaltic dysfunction remains controversial, but their severity is inter related. ${ }^{6}$ Attention has been drawn to peristaltic abnormalities in patients who have oesophageal strictures ${ }^{78}$ but not to the presence of mucosal inflammation.

If the severity of oesophagitis and the diameter of the stricture are included in a generalised linear model, it is found that $66 \%$ of the variation in the dysphagia score is accounted for (as shown by the coefficient of multiple determination).

In clinical practice, treating and healing oesophagitis may sometimes improve patients' symptoms, though it has not been shown that such treatment has any impact on associated peristalic dysfunction. ${ }^{9}$ This would support the view that the severity of mucosal inflammation, may be more important than peristaltic dysfunction in causing dysphagia. Our results are compatible with this argument, showing that oesophagitis in patients with strictures tends to aggravate the symptom of dysphagia independently from the degree of stenosis.

The results lead to the obvious therapeutic implication, which may need to be tested in a trial, that apart from oesophageal stricture dilatation it is of equal importance that associated oesophagitis should be treated. Antireflux treatment which healed oesophagitis might reduce the recurrence of strictures (but has not so far been shown to do so), but may also decrease dysphagia by reducing the associated mucosal inflammation. A trend for dysphagia and oesophagitis to improve using $\mathrm{H}_{2}$-blockers is reported ${ }^{111}$; ; such improvement in oesophagitis may be more profound with more powerful agents such as proton pump inhibitors.

Our results show that stricture diameter and 
severity of oesophagitis together account for twothirds of the variation in dysphágia in patients with benign strictures. Possible additional contributory factors include the presence or absence of teeth, ${ }^{12}$ the quantity and content of saliva and its potential to be stimulated, and also the degree of peristaltic abnormality (although this may overlap with the presence of stenosis or inflammation). Nevertheless it seems unlikely that the addition of these factors will account for a large part of the remaining variation in dysphagia score, as we have already accounted for two thirds of the variation in dysphagia score of these patients by diameter and oesophagitis.

1 Triadafilopoulos G. Nonobstructive dysphagia in reflux esophagitis. Am $\mathcal{F}$ Gastroenterol 1989; 6: 614-8.

2 Dakak M, Bennet JR. A new dysphagia score with objective validation. $\mathcal{F}$ Clin Gastroenterol 1992; 14: 99-100.

3 Dyet JF, Bennett JR, Buckton G, Ashworth D. The radio- logical measurement of oesophageal stricture diameter. Clin Radiol 1983; 34: 647-9.

4 Draper N, Smith H. Applied regression analysis. 2nd ed. John Wiley, New York 1980: 33-90.

5 Goldschmid S, Boyce Jnr HW, Brown JI, Brady Pg, Nord HJ, Lyman GH. A new objective measurement of esophageal lumen patency. Am $\mathcal{F}$ Gastroenterol 1989; 84: 1255-8.

6 Kahrilas PJ, Dodds WJ, Hogan WJ, Kern M, Arndorfer RC Reece A. Esophageal peristaltic dysfunction in peptic esophagitis. Gastroenterology 1986; 91: 897-904.

7 Ahtaridis G, Snape WJ, Cohen S. Clinical and manometric findings in benign peptic strictures of the esophagus. Dig Dis Sci 1979; 24: 858-61.

8 Little AG, Correnti FS, Calleja IJ, Montag AG, Chow YC, Ferguson MK, et al. The effect of incomplete obstruction on feline esophagus function with a clinical correlation. Surgery 1986; 100: 430-6.

9 Baldi F, Ferrarini F, Longanesi A, Angeloni M, Ragazzini M, Miglioli $M$, et al. Oesophageal function before, during, and after healing of erosive oesophagitis. Gut 1988; 29: 157-60.

10 Wesdrop E, Bartelsman J, Pape K, Dekker W, Tytgat GN. Oral cimetidine in reflux esophagitis: a double blind controlled trial. Gastroenterology 1978; 74: 821-4.

11 Ferguson R, Dronfield MW, Atkinson M. Cimetidine in treatment of reflux oesophagitis with peptic stricture. $B M \mathcal{F}$ 1979; 2: 472-4.

12 Maxton DG, Ainley CC, Grainger SL, Morris RW, Thompson RPH. Teeth and benign oesophageal stricture. Gut 1987; 28: 61-3. 